\title{
Atributos físicos do solo na cultura da mandioca sob manejo diferenciado
}

No Pará a atividade de mandiocultura exerce forte influência socioeconômica e alimentar para muitas famílias. Contudo sabe-se que o rendimento por hectare no estado ainda é aquém do esperado, pois um dos limitantes de produtividade são as formas de manejo, podendo ocasionar boas ou más alterações na estrutura do solo, devido à complexidade e interação entre seus atributos físicos, químicos e biológicos. Assim, o objetivo neste estudo foi avaliar os atributos físicos do solo em plantio de mandioca sob manejo diferenciado com o uso de estatística multivariada. A área experimental está localizada na comunidade de Boa Esperança, município de Santarém, estado do Pará, Brasil, sendo avaliado as práticas de manejo: controle de plantas infestantes, diferentes sistemas de irrigação, correção de acidez do solo e densidade populacional, onde foram coletadas amostras deformadas compostas na profundidade de 0-20 cm e amostras indeformadas de 0-5 e 15-20 cm por parcela. Foram determinados a granulometria, densidade do solo, densidade de partícula e porosidade total. Os dados foram submetidos a estatística descritiva e análise de componentes principais, sendo que nos componentes principais foram identificados a formação de grupos apenas nos tratamentos com capina manual e testemunha. $O$ tratamento testemunha demonstrou a diminuição da densidade do solo, mas neste mesmo manejo se observou o aumento da densidade do solo com a adição de calcário. Enquanto que no tratamento com capina manual + calcário apresentou baixa densidade do solo.

\section{Physical attributes of soil in candle culture under differentiated management}

\begin{abstract}
In Para, mandioculture activity exerts a strong socioeconomic and food influence for many families. However, it is known that the yield per hectare in the state is still less than expected, since one of the limiting factors of productivity are the forms of management, which can cause good or bad changes in soil structure due to the complexity and interaction between its physical, chemical and biological. Following this reasoning this work aimed to demonstrate the interactions physical attributes of soil in the cassava crop under different management using multivariate statistical techniques. The study was carried out in an experimental area located in the community of Boa Esperança, Santarém-Pará, with dimensions of $75 \times 32 \mathrm{~m}$, with different management systems in 36 plots, where deformed samples were collected at 0-20 cm depth and undifferentiated samples of 0-5 and $15-20 \mathrm{~cm}$ per plot. The physical attributes were: granulometry, soil density, particle density and total porosity. The classification of the accessions into groups was made by two methods: descriptive analysis and analysis of main components in which the formation of groups was identified only in the treatments with manual weeding and control of the experiment. The control treatment showed the decrease of soil density, but in this same management the increase of soil density with the addition of calcareous was observed. The treatment with manual weeding plus addition of calcareous showed low values of soil density and of clay.
\end{abstract}

Keywords: Family farming; Multivariate statistics; Physical properties of soil.

\section{Topic: Ciências do Solo}

Reviewed anonymously in the process of blind peer.
Received: 02/02/2021

Approved: 25/02/2021
Douglas Jhone Brito Lins (D)

Universidade Federal do Oeste do Pará, Brasil

http://lattes.cnpq.br/9124315287288235

douglasjhonebl@gmail.com

Iolanda Maria Soares Reis (iD)

Universidade Federal do Oeste do Pará, Brasil

http://lattes.cnpq.br/9591454475619777

http://orcid.org/0000-0001-6619-0730

iolandareis@outlook.com

\section{Eloi Gasparin (iD)}

Universidade Federal do Oeste do Pará, Brasil

http://lattes.cnpq.br/2243552161227323

http://orcid.org/0000-0001-9127-694X

eloigasparim@hotmail.com

\author{
Carlos Ivan Aguilar Vildoso id \\ Universidade Federal do Oeste do Pará, Brasil \\ http://lattes.cnpq.br/5002023727810298 \\ http://orcid.org/0000-0001-7730-7535 \\ vildoso@hotmail.com \\ Eliandra de Freitas Sai (iD \\ Universidade Federal do Oeste do Pará, Brasil \\ http://lattes.cnpq.br/6995722118209601 \\ http://orcid.org/0000-0003-3703-4485 \\ eliandra.sia@hotmail.com \\ Maria Lita Padinha Corrêa Romano ic \\ Universidade Federal do Oeste do Pará, Brasil \\ http://lattes.cnpq.br/0796310101196787 \\ http://orcid.org/0000-0002-7357-3796 \\ litapc10@hotmail.com
}

\section{Referencing this:}

LINS, D. J. B.; REIS, I. M. S.; GASPARIN, E.; VILDOSO, C. I. A.; SIA, E. F.; ROMANO, M. L. P. C.. Atributos físicos do solo na cultura da mandioca sob manejo diferenciado. Revista Ibero Americana de Ciências Ambientais, v.12, n.2, p.46-56, 2021. DOI:

http://doi.org/10.6008/CBPC2179-6858.2021.002.0006 


\section{INTRODUÇÃO}

A mandioca (Manihot esculenta Crantz) é cultivada praticamente em todo o território nacional destacando-se como um dos principais alimentos produzidos e consumidos, sendo uma cultura tradicional e originária do Brasil. É cultivada principalmente em pequenas propriedades rurais, devido a sua rusticidade e boa capacidade de produção em condições adversas (FIALHO et al., 2011). De acordo com a FAO, o Brasil é o quinto maior produtor mundial de mandioca, com 17,64 milhões de toneladas. O Pará é o estado com a maior produção de raiz de mandioca do Brasil, com safra estimada em 3,9 milhões de toneladas, seguido por Paraná e Bahia com 3,7 e 1,8 milhões de toneladas respectivamente para o ano de 2019. Devido à importância desta cultura e o expressivo comércio nas principais cidades, o Estado do Pará apresenta o maior consumo per capita em forma de farinha, estimado em $35 \mathrm{~kg} / \mathrm{ano}$.

Na Amazônia, a época de plantio está relacionada com o período de chuvas, em que seu plantio é feito geralmente no início da estação chuvosa, o que permite o cultivo praticamente o ano todo. Esse sistema de produção consiste em corte e queima da vegetação, uso e abandono da área (pousio) (CHAVES, 2016).

O cultivo intensivo no solo, bem como seu preparo em condições inadequadas promovem alterações em sua estrutura física e consequente quedas de produtividade. A análise granulométrica é uma das ferramentas utilizadas para caracterizar a estrutura física e para que se adotem práticas adequadas de uso e manejo do solo. A granulometria interfere diretamente a diversos atributos físicos e químicos do solo, como compactação, aeração, absorção de nutrientes pelas plantas, disponibilidade hídrica e capacidade de troca de cátions (KLEIN et al., 2013).

A mandioca pode ter sua produtividade limitada devido a fatores físicos do solo. O preparo do solo para o cultivo da mandioca é tradicionalmente feito por uma aração e duas gradagens, mas este tipo de manejo conforme Gabriel Filho et al. (2000) pode ocasionar compactação, erosão e empobrecimento progressivo do solo, com consequente diminuição na produtividade. Desta forma, torna-se evidente que o baixo emprego de tecnologias na produção da mandioca ainda é um dos principais fatores para a baixa produtividade e rendimento.

Para estimar as inter-relações das propriedades físicas do solo, uma das ferramentas úteis para esse propósito é a estatística multivariada, pois está dentre outras avaliações de características múltiplas, é capaz identificar e relacionar os atributos físicos do solo com os sistemas de manejo. Com as técnicas de análise multivariada, é possível explicar o máximo de intercorrelação entre as variáveis e descobrir quais delas contribuem mais para a caracterização e, ou, alteração do solo (PRAGANA et al., 2012).

Neste sentido, o objetivo deste trabalho foi avaliar os atributos físicos do solo em cultivo de mandioca com manejo diferenciado aplicando a análise de componentes principais como análise exploratória.

\section{MATERIAIS E MÉTODOS}

Este trabalho foi realizado em área de agricultor familiar, localizada na comunidade Boa Esperança, município de Santarém, Pará, Brasil, sob coordenada geográfica: $2^{\circ} 44^{\prime} 24,7^{\prime \prime S}$ de latitude sul e $54^{\circ} 31^{\prime} 33,2^{\prime \prime} \mathrm{W}$ 
de longitude oeste e altitude média de 145 m, as dimensões da área experimental foi 75 x 32 m, totalizando $2.400 \mathrm{~m}^{2}$.

A região de estudo apresenta clima tropical, com pluviosidade significativa na maioria dos meses, com uma curta época seca e não muito eficaz. Conforme Köppen e Geiger o clima é classificado como Am, com temperatura média anual de $26,4{ }^{\circ} \mathrm{C}$, a Figura 1 evidencia a média mensal em mm de precipitação na região durante o ano de 2017, ano da implantação do experimento, se observa pelo gráfico o maior regime de pluviosidade no primeiro semestre do ano na área em estudo.

O solo da área experimental é classificado como Latossolo Amarelo (EMBRAPA, 2016). A área antes do experimento era caracterizada por capoeira, no qual se gradeou para plantação de pastagem seguida de criação de bovinos. Antes da implantação do experimento realizaram-se amostragens de solo na área, para caracterização dos atributos químicos e físicos (Tabela1). A área foi preparada e adubação conforme as recomendações técnicas contidas em EMBRAPA (2007), em seguida, foi implantada a cultura de mandioca, variedade bem-te-vi, em 15 de março de 2017.

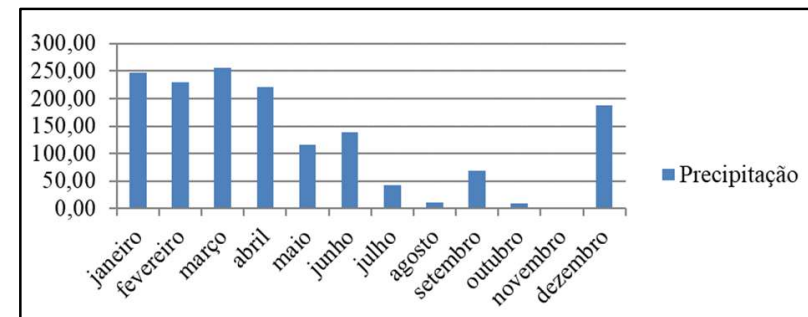

Figura 1: Médias mensais de precipitação em $\mathrm{mm}$ no ano de 2017.

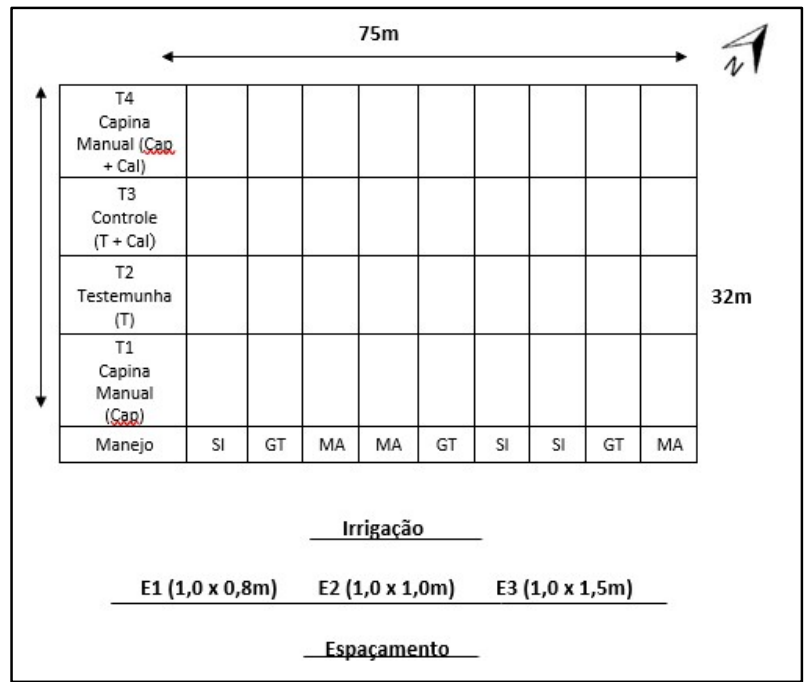

Figura 2: Croqui da área experimental, ilustrando a malha de amostragem representando as amostras compostas e as amostras indeformadas com seus respectivos manejos: SI - sem irrigação; GT gotejamento; MA - microaspersão. Fonte: Adaptado de Souza (2018).

As diferentes práticas de manejo da área foram: controle de plantas infestantes, diferentes sistemas de irrigação, correção de acidez do solo e densidade populacional, sendo que os diferentes tipos de irrigação foram (Microaspersão - MI; Gotejamento - GT; Sem Irrigação - SI) com espaçamento $(1,0$ x 0,8; 1,0 x 1,0; 1,0 x 1,5 m) e o controle de plantas daninhas foram (Controle Manual; Sem Controle) (Figura 2).

Tabela 1: Resultados da análise química e física de solo da área estudada, antes da implantação do experimento. Onde MO - Matéria Orgânica; SB - Soma de Bases; T - Capacidade de Troca Catiônica; V - Saturação por Bases.

\begin{tabular}{|c|c|c|c|c|c|c|c|c|c|c|c|c|c|c|c|}
\hline \multicolumn{2}{|c|}{ Ph } & \multirow{2}{*}{\multicolumn{2}{|c|}{$\frac{P \quad K}{\mathrm{mg} / \mathrm{dm} 3}$}} & \multirow{2}{*}{\multicolumn{3}{|c|}{$\begin{array}{l}\mathrm{Ca}+\mathrm{Mg} \mathrm{Ca} \quad \mathrm{Mg} \\
---\mathrm{cmolc} / \mathrm{dm}^{3}-\mathrm{-}\end{array}$}} & \multirow[t]{2}{*}{ Al } & \multirow[t]{2}{*}{ H } & \multirow{2}{*}{$\frac{\text { M.O }}{\mathrm{g} / \mathrm{kg}}$} & \multirow{2}{*}{\multicolumn{2}{|c|}{$\begin{array}{l}\text { Areia Silte } \\
----g / k g-\end{array}$}} & \multirow[t]{2}{*}{ Argila } & \multirow{2}{*}{\multicolumn{2}{|c|}{$\begin{array}{l}\text { SB } \quad T \\
\mathrm{cmol} \mathrm{c} / \mathrm{dm}^{3}\end{array}$}} & \multirow{2}{*}{$\begin{array}{l}\mathrm{V} \\
\%\end{array}$} \\
\hline Água & $\mathrm{aCl}$ & & & & & & & & & & & & & & \\
\hline 6,1 & 5,4 & 4,0 & 43,9 & 4,6 & 3,4 & 1,2 & 0,0 & 4,0 & 37,8 & 173,0 & 168,0 & 659,0 & 4,7 & 8,7 & 54,0 \\
\hline
\end{tabular}

As análises físicas do solo, foram: granulometria, pelo método da pipeta, densidade do solo pela 
técnica do anel volumétrico, densidade de partículas pelo método do balão volumétrico e porosidade total através do método indireto, os procedimentos foram conforme metodologias copiladas em EMBRAPA (2017).

Nos meses de fevereiro a maio de 2018 foram realizadas as coletas de campo em 4 tratamentos de 36 parcelas do experimento, foram coletadas amostras deformadas compostas, com auxílio de trado holandês, na profundidade de 0 a $20 \mathrm{~cm}$ e amostras indeformadas com auxílio de anel volumétrico de aço inóx de volume conhecido, nas profundidades de 0-5 e 15-20 cm.

As amostras foram analisadas no Laboratório de Solos da Universidade Federal do Oeste do Pará, seguindo-se a metodologia copiladas em EMBRAPA (2017), para as análises de granulometria, densidade de partícula, densidade do solo e porosidade.

Os resultados foram submetidos à análise estatística descritiva. Após a padronização das variáveis com média nula e variância unitária $(\mu=0, \sigma=1)$, os dados foram submetidos à Análise de Componentes Principais (ACP), estes foram estudados de acordo com o tratamento quanto ao uso de calcário ou não, tipo de trato cultural de capina manual ou testemunha (sem capina) alternada no experimento.

O critério escolhido para a seleção do número de componentes principais foi: autovalores acima de 1,00, que conseguiram resumir uma variância acumulada acima de 70\% (HAIR JÚNIOR et al., 2009). Todas as análises estatísticas foram processadas no programa Statistica 7.0.

\section{RESULTADOS E DISCUSSÃO}

Considerando todos os tratamentos, as análises demonstraram que o teor de areia variou de 3 a 11\%, os de silte variou de 10 a $35 \%$ e de argila de 60 a 83\%, de maneira geral não apresentando grande alteração entre as amostras estudadas independente do tratamento. De acordo com os resultados, estes solos são caracterizados de textura argilosa a muito argilosa, corroborando com estudos da Embrapa (2016), que classificaram solos da região como predominantemente argilosos.

A cultura da mandioca expressa melhor adaptação em solos arenosos ou de textura média facilitando a colheita. Os solos argilosos devem ser usados com restrições, pois o mesmo pode prejudicar o crescimento e a colheita das raízes, também pode ocorrer podridão devido o maior risco de encharcamento nestes solos (FIALHO et al., 2011).

A densidade de partícula variou de 2,1 a $2,66 \mathrm{~g} \mathrm{~cm}^{-3}$, sendo assim esse resultado está próximo da média usual para densidade de partícula em solos minerais brasileiros que é de $2,65 \mathrm{~g} \mathrm{~cm}^{-3}$.

A densidade do solo variou de 1 a $1,3 \mathrm{~g} \mathrm{~cm}^{-3}$ indicando ser uma densidade favorável ao desenvolvimento das raízes. Conforme Reichert et al. (2003) os teores críticos de densidade para solos argilosos situam-se entre 1,4 a 1,6 $\mathrm{g} \mathrm{cm}^{-3}$. Para Reinert et al. (2001) de maneira generalizada baseado nos experimentos e resultados disponíveis na literatura esses valores críticos situam-se acima de $1,45 \mathrm{~g} \mathrm{~cm}^{-3}$ para solos de textura argilosa.

A literatura não aponta um índice específico ou ideal de densidade do solo para as raízes da cultura da mandioca, pois esta variável está relacionada dentre outras coisas com o manejo e a textura. Mas estudos 
realizados por Argenton et al. (2005) constataram, em Latossolo Vermelho argiloso, a deficiência de aeração inicia-se com densidade do solo próximo de $1,30 \mathrm{~g} \mathrm{~cm}^{-3}$. Para Klein (2006), na mesma classe de solo, baseado no intervalo hídrico ótimo, observou que a densidade limitante foi de $1,33 \mathrm{~g} \mathrm{~cm}^{-3}$ e a densidade ótima com $1,08 \mathrm{~g} \mathrm{~cm}^{-3}$.

A porosidade total oscilou entre 0,37 a $0,54 \mathrm{~m}^{3} \mathrm{~m}^{-3}$. Para Reichardt et al. (2004) a porosidade total, nesse tipo de solo, varia de 0,52 a $0,61 \mathrm{~m}^{3} \mathrm{~m}^{-3}$. A densidade e a porosidade são inversamente proporcionais quando ocorre o aumento de uma, há a redução da outra (CAMARGO, 1999).

A análise descritiva dos dados do tratamento não apresentou variação, sugerindo que os resultados não foram afetados nos parâmetros avaliados como demonstra a Tabela 2. Os efeitos das variáveis se aproximaram aos trabalhos publicados para solos argilosos. Onde os valores médios dos parâmetros de granulometria do solo, distribuído em areia 5,14\%, silte $18,52 \%$ e argila $76,32 \%$ indicaram proximidade com os valores da região, que variam de 0,8 a $81 \% ; 0,2$ a 42,6\% e de 8 a 97\%, para frações de areia, silte e argila total, respectivamente (RODRIGUES et al., 2010).

Tabela 2: Estatística descritiva dos dados da areia, argila e silte, expressos em \%, densidade de partículas e densidade do solo apresentados em $\mathrm{g} \mathrm{cm}^{-3}$, e porosidade total em $\mathrm{m}^{3} \mathrm{~m}^{-3}$.

\begin{tabular}{llllll}
\hline Variáveis & Valor $\mathbf{N}$ & Média & Mínimo & Máximo & Desvio Padrão \\
\hline Porosidade Total & 36 & 0,46 & 0,37 & 0,54 & 0,03 \\
Densidade do Solo & 36 & 1,23 & 1,08 & 1,32 & 0,05 \\
Densidade da Partícula & 36 & 2,29 & 2,10 & 2,66 & 0,14 \\
\%Argila & 36 & 76,32 & 60,69 & 83,94 & 5,53 \\
\% Silte & 36 & 18,52 & 10,25 & 35,46 & 5,77 \\
\% Areia total & 36 & 5,14 & 3,19 & 11,85 & 1,75 \\
\hline
\end{tabular}

O valor médio da porosidade total foi de $0,46 \mathrm{~m}^{3} \mathrm{~m}^{-3}$ sugerindo pouca interferência do sistema de preparo aplicado se comparado com estudos em Latossolo Vermelho argiloso realizados por Secco et al. (1997), onde encontrou-se porosidade total variando entre 0,53 e $0,57 \mathrm{~m}^{3} \mathrm{~m}^{-3}$ em diferentes sistemas de manejo.

A densidade do solo é uma variável que expressa o grau de bloqueio mecânico que inibe ou diminui o crescimento das raízes. $O$ valor médio de densidade do solo foi de $1,23 \mathrm{~g} \mathrm{~cm}^{-3}$. Em estudo realizado por Collares et al. (2006) em um Argissolo demonstraram que o valor crítico de densidade do solo baseado no intervalo hídrico ótimo (IHO) para a cultura do feijoeiro foi de $1,75 \mathrm{~g} \mathrm{~cm}^{-3}$ limitando seu desenvolvimento e crescimento. Camargo et al. (1997) avaliam que $1,55 \mathrm{~g} \mathrm{~cm}^{-3}$ como sendo um valor crítico de densidade em solos franco-argilosos a argilosos. Em trabalho com batata doce, Agbede et al. (2009) analisaram que o aumento da densidade do solo de 1,1 para $1,4 \mathrm{~g} \mathrm{~cm}^{-3}$ reduziu o rendimento desses tubérculos em (35\%) e (89\%).

Na densidade de partícula evidenciou-se média de $2,29 \mathrm{~g} \mathrm{~cm}^{-3}$ essa variável é um atributo físico do solo estável, assim sendo não sujeito as mudanças devido ao manejo. Considerando que os constituintes minerais predominantes nos solos são quartzo, silicatos de alumínio e feldspato, a literatura comumente utiliza a densidade de partícula de $2,65 \mathrm{~g} \mathrm{~cm}^{-3}$ representando o valor médio desses minerais (REICHARDT et al., 2004). No experimento, foi observado valor médio de densidade da partícula abaixo aos da literatura.

Para a análise de ACP foi apresentado um gráfico biplot (Figura 3). O gráfico biplot pode ser usado 
para verificar a importância e a contribuição de cada variável para explicação da variância total, assim como, suas interações. No T1, tratamento que recebeu somente capina manual os componentes principais (CP1xCP2) obtiveram 77,18\% da variação total dos dados, onde o primeiro componente principal possui $40,17 \%$ da variância e o segundo $37,01 \%$ como mostra a Figura 3A.

$\mathrm{O}$ T2, tratamento com parcelas testemunha os componentes principais (CP1xCP2), apresentaram 86,95\% da variância total, onde o CP1 alcançou 58,29\% e o CP2 28,66\% de variância (Figura 3B). Já no T3, tratamento com calcário, a variação total foi de 70,59\%, em que a CP1 obteve $45,64 \%$ e o CP2 24,95\% de variância (Figura 3C). No tratamento T4, onde o manejo foi feito com capina manual e calcário, foi observado $72,09 \%$ de variação total com CP1 no valor de $46,25 \%$ e o CP2 25,84\% (Figura 3D).

Na Tabela 3 é possível observar as correlações das variáveis e dos componentes principais (ACP), as variáveis foram descritas de acordo com os atributos do solo e seu comportamento em diferentes manejos.
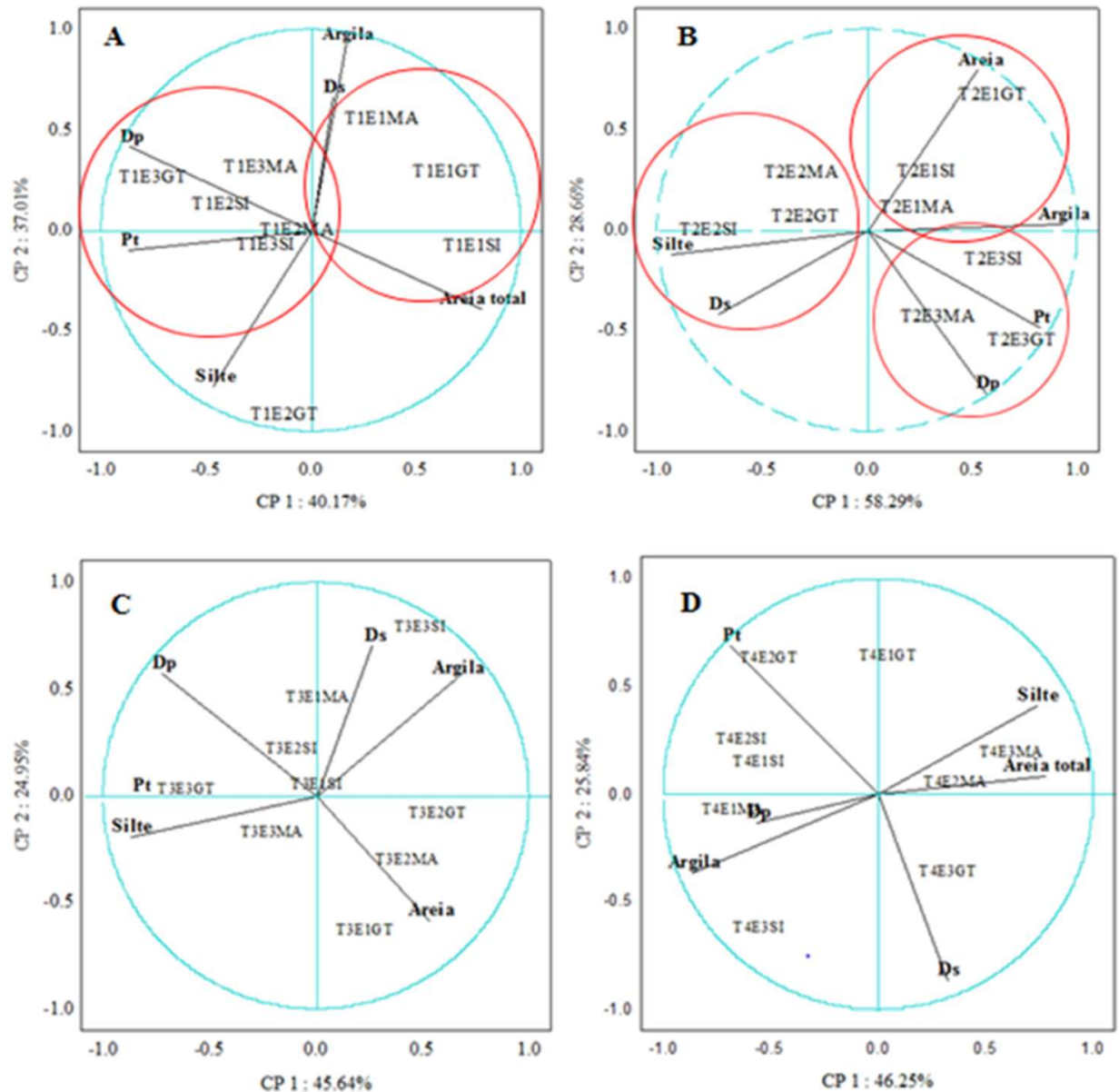

Figura 3: Gráficos biplot evidenciando as interações do manejo dos tratamentos com as propriedades físicas analisadas. A) T1 = tratamento com capina manual; B) T2 = tratamento sem calcário, sem capina; C) T3 = tratamento sem capina + calcário; D) T4 = tratamento com capina + calcário; E1, E2, E3 = espaçamentos $1 \times 0,8,1 \times 1$ e $1 \times 1,5 \mathrm{~m}$, respectivamente; $\mathrm{SI}$ = sem irrigação; $\mathrm{GO}$ = gotejamento e $\mathrm{MA}=$ microaspersão.

No T1, o componente principal 1 revelou autovetores negativos para porosidade total e densidade de partícula e positivos para areia total. No componente principal 2 observou-se autovetores argila positivo e silte negativo, sendo estas variáveis que melhor se correlacionaram com CP1 e CP2. Já o T2, demonstrou autovetores positivos para porosidade total e argila e negativos para densidade do solo e silte, com o CP2 do mesmo tratamento com autovetor negativo para densidade da partícula e positivo para areia total. Observa- 
se a formação de grupos apenas nos tratamentos 1 e 2 com capina manual e testemunha respectivamente (Figura 3A, 3B), onde no T1, foi possível verificar que o espaçamento 2 e 3, foram segregados em um grupo estando fortemente correlacionado com porosidade total e densidade do solo, enquanto que o espaçamento 1, correlacionou principalmente com areia total. No T2, foi identificado a divisão em 3 grupos de acordo com o espaçamento, o E2, apresentou alta correlação com silte e de densidade do solo, E1, com alta correlação com areia total e E3 porosidade total e densidade da partícula.

Tabela 3: Interação entre as variáveis estudadas e os componentes principais. Onde CP1: componente principal 1; CP2: componente principal 2; Atrib: atributos; PT: porosidade total; DS: densidade do solo; DP: densidade da partícula; ARG: argila; SIL: silte; AT: areia total.

\begin{tabular}{|c|c|c|c|c|c|c|c|c|}
\hline \multicolumn{9}{|c|}{ Componentes Principais } \\
\hline \multirow{3}{*}{ Atrib. } & \multirow{2}{*}{\multicolumn{2}{|c|}{$\begin{array}{l}\text { Tratamento } 1 \\
\text { Capina manual }\end{array}$}} & \multirow{2}{*}{\multicolumn{2}{|c|}{$\begin{array}{l}\text { Tratamento } 2 \\
\text { Testemunha }\end{array}$}} & \multirow{2}{*}{\multicolumn{2}{|c|}{$\begin{array}{l}\text { Tratamento } \mathbf{3} \\
\text { Testemuha+Calcário }\end{array}$}} & \multirow{2}{*}{\multicolumn{2}{|c|}{$\begin{array}{l}\text { Tratamento } 4 \\
\text { Capina+Calcário }\end{array}$}} \\
\hline & & & & & & & & \\
\hline & $\mathrm{CP} 1$ & $\mathrm{CP} 2$ & $\mathrm{CP} 1$ & $\mathrm{CP} 2$ & $\mathrm{CP} 1$ & $\mathrm{CP} 2$ & $\mathrm{CP} 1$ & $\mathrm{CP} 2$ \\
\hline PT & $-0,87$ & $-0,09$ & 0,82 & $-0,48$ & $-0,82$ & 0,05 & $-0,68$ & 0,68 \\
\hline DS & 0,10 & 0,65 & $-0,70$ & $-0,42$ & 0,34 & 0,70 & 0,32 & $-0,86$ \\
\hline DP & $-0,85$ & 0,41 & 0,56 & $-0,80$ & $-0,63$ & 0,66 & $-0,56$ & $-0,13$ \\
\hline ARG. & 0,16 & 0,91 & 0,92 & 0,02 & 0,66 & 0,47 & $-0,86$ & $-0,37$ \\
\hline SIL. & $-0,46$ & $-0,77$ & $-0,93$ & $-0,12$ & $-0,88$ & $-0,17$ & 0,73 & 0,40 \\
\hline AT & 0,80 & $-0,38$ & 0,52 & 0,79 & 0,53 & $-0,45$ & 0,77 & 0,07 \\
\hline
\end{tabular}

A atuação do manejo no tratamento com capina, favoreceu a diminuição da porosidade em e aumento da densidade do solo. Quanto maior a densidade do solo ou a massa específica do solo seco, menor é a porosidade total do solo, seja pela natureza e arranjamento das partículas sólidas ou pela compactação (PREVEDELLO, 1996). O mesmo se observou em avaliações de atributos físicos do solo feitas por Pezarico et al. (2013) em sistema agroflorestal (SAF) no qual constatou-se que o aumento da densidade do solo provoca diminuição na porosidade total. É importante destacar que a porosidade do solo também está relacionada com o tipo de solo, de cultura, biologia, macroestrutura e manejo.

O alto teor de argila (Figura 4A e Tabela 3) se deve ao fato de que os solos da região são predominantemente argilosos. Solos argilosos são mais susceptíveis a compactação devido às interações de manejo, umidade, plasticidade e coesão. De acordo com Rosolem et al. (1999), solos com conteúdo de argila acima de 40 \% têm maior resistência à penetração, com isso pode se deduzir que quanto mais argila presente no solo, menor o tamanho médio dos poros e maior a resistência à penetração considerando uma determinada densidade.

Mas para Klein (2008) em solos com maiores teores de argila, em função das suas propriedades químicas e físicas, são melhores para fins agrícolas, sendo que a distribuição do tamanho das partículas do solo interfere diretamente no grau de compactação, na disponibilidade de água, na capacidade de trocas de cátions, na dosagem de nutrientes e corretivos. Reichert et al. (2007) mostram que o processo de compactação do solo aumenta sua densidade, diminui a porosidade total, e simultaneamente, diminui a condutividade hidráulica.

A densidade de partículas, como é um atributo físico do solo estável, portanto não sujeito as alterações devido ao manejo, manifestou resultados esperados relacionados aos da literatura. Observa-se que esta variável está intimamente ligada a porosidade total dentro do mesmo grupo (Figura 3A), bem como 
no mesmo grupo do tratamento 2 na Figura 3B. Corroborando com estudos feitos por Lopes et al. (2015) no qual relacionou que áreas com maior densidade da partícula são também as áreas com maior porosidade total.

No T2, houve uma melhor divisão e distribuição das variáveis no que diz respeito ao aspecto físico do solo, indicando que devido ao solo estar ocupado com vegetação e consequentemente com maior teor de matéria orgânica em sua superfície, houve intervenção, neste aspecto, na configuração física do mesmo, corroborando com Mielniczuk (2008) que relata que existe forte relação do teor de matéria orgânica com funções físicas do solo como a resistência à erosão, a estabilidade dos agregados e da estrutura, a lixiviação de nutrientes e a infiltração e retenção de água. Infere-se que ocorreu interferência da MO neste tratamento, devido ao espaçamento usado e a densidade da cultura. Isso pode ser evidenciado na relação inversa entre porosidade total e densidade do solo nesse manejo, onde se verifica que a correlação da densidade do solo é negativa enquanto a porosidade total é positiva (Figura 3B e Tabela 3). Uma das condições que atuam nestes atributos é o teor de matéria orgânica, confirmada por Klein (2008) no qual menciona que solos com maior teor de MO apresentam menor densidade, como a densidade e a porosidade total do solo são propriedades com elevada relação entre si (LOPES et al., 2011) e relacionadas com alterações no volume de solo, elas interferem diretamente na compactação do solo (REICHERT et al., 2007).

As variáveis silte e argila com influência negativa e positiva respectivamente, foram as que mais correlacionaram nesse tratamento (Figura 3B e Tabela 3). Contudo, a textura do solo é uma das características físicas mais estáveis, representada pela distribuição quantitativa das partículas de areia, silte e argila quanto ao tamanho (FERREIRA, 2010).

Pelo cálculo da relação silte/argila concluiu-se que este solo apresenta elevado grau de intemperismo, explicando desse modo os baixos teores de silte com valor abaixo de 0,6 para textura argilosa ou muito argilosa (EMBRAPA, 2018). Este parâmetro indica apenas o estágio de desenvolvimento dos solos, não havendo implicação no uso agronômico. Os solos argilosos podem implicar em baixa permeabilidade e alta capacidade de retenção de água, contudo em estudos realizados por Ferreira et al. (1999) em Latossolos, os quais concluíram que a permeabilidade do solo aumentou com o teor de argila.

Considerando que a densidade de partícula é um atributo estático, onde mudanças só seriam perceptíveis ao longo do tempo, a literatura geralmente associa seu valor abaixo da média usual de 2,65 g $\mathrm{cm}^{-3}$, quando indica a presença de partículas menos densas que seus minerais constituintes e predominantes nos solos, que são o quartzo, os feldspatos e os silicatos de alumínio coloidais.

Isso pode estar associado aos maiores conteúdos de material orgânico, cujo baixo peso específico contribui para diminuir a densidade de partículas principalmente na superfície onde ela é mais abundante (RIBEIRO et al., 2007). A porosidade total dentro do mesmo grupo apresentou uma variação positiva, ao contrário do que ocorreu no manejo com capina manual, essa diferença está associada com o decréscimo da densidade do solo, no tratamento 2 .

Os tratamentos 3 e 4 onde houve correção da acidez, não foi possível observar a formação de grupos. Esses tratamentos foram praticados da mesma forma que os tratamentos 1 e 2 onde se diferenciou apenas 
com a adição de calcário. Os atributos que mais discriminaram no tratamento 3 (testemunha + calcário) foram silte, porosidade total e densidade do solo (Figura $3 \mathrm{C}$ ), sendo que a maior correlação do CP1 foi com as variáveis porosidade total e silte. No entanto, a variável que melhor correlacionou no CP2 foi a densidade do solo.

O T4, tratamento manejado com capina manual e adição de calcário também não formou grupos como mostra a Figura 3D. Devido aos seus maiores valores as variáveis que mais discriminaram nesse tratamento foram argila, silte, areia total, correlacionando com CP1 e densidade do solo, com CP2. Valores baixos de densidade do solo são favoráveis ao crescimento e desenvolvimento do sistema radicular das plantas.

Na literatura não há consenso sobre os benefícios de calcário nas propriedades físicas do solo. Estudos que aborda os efeitos da calagem e gessagem nas propriedades físicas de um Latossolo (BERTOLLO, 2014), concluiu que houve uma diminuição da densidade do solo com aplicação de 2 toneladas por hectare de calcário em sistema de manejo convencional, mas explica que essa redução depende da dose aplicada, e que a densidade obteve acréscimo em maiores doses de calagem.

De acordo com Spera et al. (2008), os quais analisaram os efeitos do calcário relacionados com a compactação do solo, conforme se aumentava a aplicação de calcário, ocorreu a diminuição da macroporosidade e ampliação da densidade do solo, propondo alterações estruturais do efeito do calcário na compactação do solo. Contudo, Tormena et al. (1998), em experimento realizado para medir fatores que interferem na compactação do solo em plantio direto, verificaram que a calagem não afetou, significativamente, nenhuma das propriedades físicas analisadas incluindo densidade do solo e porosidade total. Neste estudo não ficou evidenciada a ação da água, com ausência de irrigação, microaspersão ou gotejamento, isto deve-se ao fato de no decorrer do projeto ocorreu interrupção dos sistemas de irrigação, devido a dificuldades técnicas na comunidade.

\section{CONCLUSÕES}

A ACP permitiu a formação de grupos apenas nos tratamentos 1 e 2 , capina manual e testemunha respectivamente, sem correção de acidez, separando os mesmo por espaçamento. Os atributos que mais variaram percentualmente no tratamento 1 foram porosidade total e teor de argila e no tratamento 2 foram teor de silte e argila.

Nas condições edafoclimáticas da área desse experimento o tratamento testemunha caracterizou-se pela diminuição da densidade do solo, favorecendo fisicamente suas características. Mas o mesmo tipo de manejo com adição de calcário demonstrou o aumento da densidade do solo e diminuição da porosidade total o que gera impedimento físico ao desenvolvimento das raízes das culturas.

AGRADECIMENTOS: Agradecemos ao Banco da Amazônia, pelo financiamento do projeto 'Manejo sustentável de mandioca em áreas com podridão de raízes', que deu origem este trabalho. 


\section{REFERÊNCIAS}

AGBEDE, T. M.; ADEKIYA, A. O.. Tillage effects on soil properties and performance of sweet potato on an Alfisol in Southwestern Nigeria. Eur. J. Sustain. Agric., v.3, p.561-568, 2009.

ARGENTON, J.; ALBUQUERQUE, J. A.; BAYER, C.; WILDNER, L. P.. Comportamento de atributos relacionados com a forma da estrutura de Latossolo Vermelho sob sistemas de preparo e plantas de cobertura. R. Bras. Ci. Solo, 29:425-435, 2005. DOI: http://doi.org/10.1590/S0100-06832005000300013

BERTOLLO, A. M.. Propriedades físicas de um latossolo após calagem, gessagem em manejo de solos. Dissertação (Mestrado em Agronomia) - Universidade Federal de Santa Maria, Frederico Westphalen, 2014.

CAMARGO, O. A.; ALLEONI, L. R. F.. Compactação do solo e o desenvolvimento das plantas. Piracicaba: Esalq, 1997.

CAMARGO, C. M. S.. Compactação do solo causada pela colheita de Pinus taeda, pelo sistema fuste (Tree length). Dissertação (Mestrado em Engenharia Florestal) Universidade Federal do Paraná, Curitiba, 1999.

COLLARES, G. L.; REINERT, D. J.; REICHERT, J. M.; KAISER, D. R.. Qualidade física do solo na produtividade da cultura do feijoeiro num Argissolo. Pesq. Agropec. Bras., Brasília, v.41, n.11, p.1663-1674, 2006. DOI:

https://doi.org/10.1590/S0100-204X2006001100013

CHAVES, R. S.. Tipos de solo e a orientação para o mercado influenciam na escolha das variedades de mandioca (Manihot esculenta Crantz) nos sistemas de produção do baixo rio Tapajós, Pará. Dissertação (Mestrado em Botânica) - Instituto Nacional de Pesquisas da Amazônia, Manaus, 2016.

EMBRAPA. Empresa Brasileira de Pesquisa Agropecuária. Recomendações de adubação e calagem para o estado do Pará. EMBRAPA, 2007.

EMBRAPA. Empresa Brasileira de Pesquisa Agropecuária. Mapas de solos e de aptidão agrícola das áreas alteradas do estado do Pará. Embrapa Solos, 2016.

EMBRAPA. Empresa Brasileira de Pesquisa Agropecuária. Manual de métodos de análises de solo. 3 ed. Brasília, 2017.

EMBRAPA. Empresa Brasileira de Pesquisa Agropecuária. Sistema Brasileiro de Classificação de Solos. 5 ed. Brasília: Embrapa, 2018.

FERREIRA, M. M.; FERNANDES, B.; CURI, N.. Influência da fração argila nas propriedades físicas de Latossolos da região sudeste do Brasil. R. Bras. Ci. Solo, v.23, p.515-524, 1999. DOI: https://doi.org/10.1590/S0100-06831999000300004

FERREIRA, M. M.. Caracterização Física do Solo. In: LIER, Q. J. V.. Física do Solo. Viçosa: SBCS, 2010. p.298.

FIALHO, J. F.; VIEIRA, E. A.. Manejo do Solo no Cultivo de Mandioca. Mandioca no cerrado: orientações técnicas. Planaltina: Embrapa Cerrados, 2011.
GABRIEL FILHO, A. G.; PESSOA, A. C. S.; STROHHAECKER, L.; HELMICH, J. J.. Preparo convencional e cultivo mínimo do solo na cultura de mandioca em condições de adubação verde com ervilhaca e aveia preta. Cienc. Rural, v.30, n.6, p.953-957, 2000. DOI: http://dx.doi.org/10.1590/S0103$\underline{84782000000600005}$

HAIR JUNIOR, J. F.; BLACK, W. C.; BABIN, B. J.; ANDERSON, R. E.; TATHAM, R. L.. Análise multivariada de dados. 6 ed. Porto Alegre: Bookman, 2009.

KLEIN, V. A.. Física do solo. Passo Fundo: Universidade de Passo Fundo, 2008.

KLEIN, V. A.. Densidade relativa: Um indicador da qualidade física de um Latossolo Vermelho. R. Ci. Agron., 5:26-32, 2006. DOI: https://doi.org/10.1590/S010384782009005000225

KLEIN, V. A.; MADALOSSO, T.; REICHERT, J. M.; SUZUKI, L. E. A. S.; VEIGA, M.; ALBUQUERQUE, J. A.; PAULETTO, E. A.. Metodologias de Controle de Qualidade de Análises Granulométricas do Solo. Cienc. Rural, Santa Maria, v.43, n.5, p.850-853, 2013. DOI: https://doi.org/10.1590/s010384782013000500015

LOPES, E. S.; OLIVEIRA, D.; RODRIGUES, C. K.; DRINCO, C. H. Avaliação da Umidade na Compactação do Solo Submetido ao Tráfego de Máquinas de Colheita Florestal. Revista Árvore, Viçosa, v.35, n.3, p.659-667, 2011. DOI: https://doi.org/10.1590/2179-8087.046413

LOPES, B. B.; CARVALHO NETO, E. O.; SOUZA, E. L. S.; RAMOS, C. M. C.; OLSZEVSKI, N.. Variabilidade espacial de atributos físicos do solo. In: SIMPÓSIO DE GEOESTATÍSTICA EM CIÊNCIAS AGRÁRIAS - SGeA, 4. Anais. Botucatu, 2015.

MIELNICZUK, J.. Matéria orgânica e a sustentabilidade de sistemas agrícolas. In: SANTOS, G. A.; SILVA, L. S.; CANELLAS, L. P.; CAMARGO, F. O.. Fundamentos da matéria orgânica do solo: ecossistemas tropicais \& subtropicais. 2 ed. Porto Alegre: Metrópole, 2008. p.654.

PEZARICO, C. R.; VITORINO, A. C. T.; MERCANTE, F. M.; DANIEL, O.. Indicadores de qualidade do solo em sistemas agroflorestais. Revista de Ciências Agrárias, v.56, n.1, p.4047, 2013. DOI: http://doi.org/10.4322/rca.2013.004

PRAGANA, R. B.; RIBEIRO, M. R.; NÓBREGA, J. C. A.; RIBEIRO FILHO, M. R.; COSTA, J. A.. Qualidade física de Latossolos Amarelos sob plantio direto na região do cerrado piauiense. R. Bras. Ci. Solo, v.36, n.5, p.1591-1600, 2012. DOI: http://dx.doi.org/10.1590/S0100-06832012000500023

PREVEDELLO, C. L.. Física do solo com problemas resolvidos. Curitiba, 1996.

ROSOLEM, C. A.; FERNANDEZ, E. M.; ANDREOTTI; M.; CRUSCIOL, C. A. C.. Crescimento radicular de plântulas de milho afetado pela resistência do solo à penetração. Pesq. Agropec. Bras. Brasília, v.34, p.821-828, 1999.

REICHARDT, K.; TIMM, L. C.. Solo, planta e atmosfera: conceito, processo e aplicações. Barueri: Manole, 2004. 
REICHERT, J. M.; REINERT, D. J.; BRAIDA, J. A.. Qualidade dos solos e sustentabilidade de sistemas agrícolas. Ciência \& Ambiente, v.27, p.29-48, 2003.

REICHERT, J. M.; SUZUKI, L. E. A. S.; REINERT, D. J.. Compactação do solo em sistemas agropecuários e florestais: identificação, efeitos, limites críticos e mitigação. Tópicos Ci. Solo, Viçosa, v.5, p.50-121, 2007.

REINERT, D. J.; REICHERT, J. M.; SILVA, V. R.. Propriedades físicas de solos em sistema plantio direto irrigado. In: CARLESSO, R.; PETRY, M. T.; ROSA, G. M.; CERETTA, C. A.. Irrigação por aspersão no Rio Grande do Sul. Santa Maria, 2001. p.114-133.

RIBEIRO, K. A.; OLIVEIRA, T. S.; MENDONÇA, E. S.; XAVIER, F. A. S.; MAIA, S. M. F.; SOUSA, H. H. F.. Qualidade do solo na cultura do cajueiro anão precoce cultivado sob diferentes sistemas de manejo. R. Bras. Ci. Solo, Viçosa, v.31, n.2, abr. 2007. DOI: https://doi.org/10.1590/S010006832007000200016

RODRIGUES, T. E.; SILVA, R. C.; SILVA, B. N. R.; SILVA, J. M. L.; VALENTE, M. A.; DARIVA, T. A.; JESUS, A. A. S.; VENTURIERI, A.. Caracterização, Mapeamento e Classificação dos Solos. Zoneamento Ecológico-Econômico da Zona Oeste do Estado do Pará: Diagnóstico Socioambiental. Belém: Embrapa Amazônia Oriental, 2010.

SPERA, S. T.; DENARDIN, J. E.; ESCOSTEGUY, P. A. V.; SANTOS, H. P.; FIGUEROA, E. A.. Dispersão De Argila em Microagregados de Solo Incubado com Calcário. R. Bras. Ci. Solo, Passo Fundo, v.32, p.2613-2620, 2008. DOI: https://doi.org/10.1590/S0100-06832008000700002

SECCO, D.; ROS, C. O.; FIORIN, J. E.; PAUTZ, C. V.; PASA, L.. Efeito de sistemas de manejo nas propriedades físicas de um Latossolo Vermelho-Escuro. Ciência Rural, Santa Maria, v.27, n.1, p.57-60, 1997. DOI: https://doi.org/10.1590/S010384781997000100011

SOUZA, L. N.. Variabilidade espacial do teor de matéria orgânica do solo em cultivo de mandioca sob manejo diferenciado. Monografia (Bacharelado) - Universidade Federal do Oeste do Pará, Santarém, 2018.

TORMENA, C. A.; ROLOFF, G.; SÁ, J. C. M.. Propriedades físicas do solo sob plantio direto influenciado por calagem, preparo inicial e tráfego. R. Bras. Ci. Solo, v.22, p.301-309, 1998. DOI: https://doi.org/10.1590/S010006831998000200016

A CBPC - Companhia Brasileira de Produção Científica (CNPJ: 11.221.422/0001-03) detém os direitos materiais desta publicação. Os direitos referem-se à publicação do trabalho em qualquer parte do mundo, incluindo os direitos às renovações, expansões e disseminações da contribuição, bem como outros direitos subsidiários. Todos os trabalhos publicados eletronicamente poderão posteriormente ser publicados em coletâneas impressas sob coordenação da Sustenere Publishing, da Companhia Brasileira de Produção Científica e seus parceiros autorizados. Os (as) autores (as) preservam os direitos autorais, mas não têm permissão para a publicação da contribuição em outro meio, impresso ou digital, em português ou em tradução. 